\title{
RISK MANAGEMENT IN PRODUCT DEVELOPMENT: RISK IDENTIFICATION, ASSESSMENT, AND MITIGATION - A LITERATURE REVIEW
}

\author{
J. Oehmen ${ }^{1}$, A. Guenther ${ }^{2}$, J. W. Herrmann ${ }^{3}$, J. Schulte ${ }^{4, \otimes}$ and P. Willumsen ${ }^{1}$ \\ ${ }^{1}$ DTU-Technical University of Denmark, Denmark, ${ }^{2}$ Copenhagen Business School, Denmark, ${ }^{3}$ University of \\ Maryland, United States of America, ${ }^{4}$ Blekinge Institute of Technology, Sweden \\ $\triangle$ jesko.schulte@bth.se
}

\begin{abstract}
This paper reviews the literature on risk management practices and methods in product design and development. Based on an expert workshop by the Risk Management Processes and Methods in Design Special Interest Group within the Design Society and literature review, three key areas are discussed: risk identification, assessment, and mitigation. In each area, researchers have described practices that are used in product development organizations, proposed new methods to support risk management processes and decision-making, and generated evidence to evaluate the effectiveness of these activities.
\end{abstract}

Keywords: design management, product development, risk management, uncertainty, literature review

\section{Introduction}

An organization that develops a new product invests its time and resources under uncertainty about whether the product will generate sufficient return on their investment. The financial outcome depends upon development cost and time, product unit cost, and sales, which in turn depend upon product performance and customer preferences, among other factors (Reinertsen, 1997). Every factor is uncertain due to potential delays, cost overruns, mistakes, higher or lower customer demand than expected, etc. Even though product development can be considered a structural way to reduce uncertainty, product development processes often do not emphasize the reduction of uncertainty, but rather focus on increasing the efficiency of the product design system (Oehmen and Seering, 2011). Thus, in the terms of Kaplan and Miles (2012), product development organizations face preventable risks and strategy risks, and they need to develop and employ sound risk management processes to mitigate and respond to these risks and increase the likelihood of a successful, profitable product.

In general, risk management involves the following key steps (Herrmann, 2015): (i) risk framing; (ii) risk identification; (iii) risk analysis; (iv) risk evaluation; (v) risk treatment); (vi) risk monitoring and review; and (vii) risk communication. The international standard ISO 31000 ("Risk Management Guidelines") places risk management in the context of a risk management framework, which is the decision-making system that will perform risk management in an organization. The steps listed above follow the steps in the ISO 31000 framework. Purdy (2010) described the key elements of ISO 31000 , 
which defines "risk" as "the effect of uncertainty on objectives". The effect could be undesirable or desirable, for uncertainty brings both threats and opportunities. However, multiple frameworks exist. Oehmen et al. (2014) compared the risk management process steps under the following frameworks: ISO 31000, the Software Engineering Institute (SEI) risk management paradigm, the INCOSE risk management standard, the U.S. Department of Defense's risk management guide, NASA's RiskInformed Decision-Making Handbook, and the PMI Project Management Body of Knowledge. They concluded that the steps in all six frameworks are similar. Oehmen et al. (2010) evaluated, for each step in the ISO 31000 framework, how well the methods discussed in the literature addressed the recommendations of the ISO 31000 framework.

This paper contributes to the understanding of product development risk management by discussing three key risk management activities, i.e. risk identification, assessment, and mitigation, and identifying techniques that can be used to perform those activities in product development projects. Through the discussion and overview of findings and techniques, this paper provides knowledge relevant for tailoring the risk management process (Oehmen et al., 2014; Škec et al., 2014; ISO, 2018; Grubisic et al., 2011). Further, the empirical basis for the evaluation of the effectiveness of risk management practices is reviewed and discussed, since it is a critical issue in the field. It is solely studies of risk management in product development that are included in this review, i.e. studies of risk management in other functions such as supply chain management or at the enterprise level are outside the scope of this paper.

\section{Research method}

Based on the purpose of providing a review of the most relevant publications on risk management in product development, this research started with an expert workshop organized by the Risk Management Processes and Methods in Design Special Interest Group (SIG) at the 21st International Conference on Engineering Design (ICED) in Vancouver, Canada, 2017. The three-hour workshop gathered experts from industry and academia to discuss the state of the art in risk management in product development. In particular, the workshop participants discussed some previous work and identified key topics in three areas: risk identification, risk assessment, and risk mitigation. In the next step, the workshop participants individually created reference lists of what they considered to be the most relevant work in these three areas. After compiling these initial lists of references, forward and backward snowballing was applied to identify additional articles (Wohlin, 2014). This resulted in a total of 61 articles (Table 1), which were reviewed for their contribution to risk management in product development. The content of the articles was analyzed and structured based in an iterative process between some of the workshop participants (the authors of this paper) based on (i) relevance of the article for risk management in product development; (ii) which step(s) of the risk management process that is addressed (e.g. risk identification, risk assessment, etc.); and (iii) the applied research method (e.g. literature review, case study, etc.).

Table 1. Number of publications included in this review from different time periods

\begin{tabular}{|c|c|c|c|c|}
\hline Years & $1960-1989$ & $1990-1999$ & $2000-2009$ & $2010-2019$ \\
\hline Number of papers & 3 & 3 & 16 & 39 \\
\hline
\end{tabular}

\section{Results}

\subsection{Risk identification}

During risk identification, a risk manager must determine the potential threats and opportunities that could occur. Three aspects are central to identifying a potential event: who (the affected stakeholders), when (at what point in the product life-cycle), and what (its impact) (Oehmen et al., 2014, NASA 2011, Akram and Pilbeam, 2015). Considering stakeholder interests during risk identification is a best practice (NASA, 2011; ISO, 2009; de Bakker, 2011; Lehtiranta, 2014; Willumsen et al., 2017). Willumsen et al. (2017) argued that risk identification should be based on the value perceptions of the 
relevant stakeholders, which determine the relevant impact categories. There are multiple, interrelated perspectives and levels to risk management in a product development organization. Potential risks include technical risks at the operational level, project risks, portfolio risks, and enterprise risks. A risk at one level may cause risks at another level, so it is important to identify the connections between these (Schulte and Hallstedt, 2018). The consequences all eventually affect fundamental objectives such as profitability, market share, reputation, and legal liability.

Oehmen et al. (2006) identified nine types of interdependencies between risks in product development portfolios: technology, budget, objectives and requirements, infrastructure and equipment, skillset and human resources, process and schedule, supplier, legal and regulatory, and finally market and customer. Risks often result from uncertainties about critical events or factors that affect the performance of a product development project. Uncertainties can be known or unknown (Oehmen and Seering, 2011). Sicotte and Bourgault (2008) identified four relevant types of uncertainty: technical and project uncertainty, market uncertainty, fuzziness, and complexity. Tegeltija et al. (2016) classified the (potential) problems in product development into two categories: (1) "tame problems" that are caused by aleatory uncertainty (such as daily disturbances), and (2) "wicked problems" that are caused by epistemic uncertainty (such as unclear requirements).

Keizer et al. (2005) identified 12 categories of risks: (1) commercial viability risks; (2) competitor risks; (3) consumer acceptance and marketing risks; (4) public acceptance risks; (5) intellectual property risks; (6) manufacturing technology risks; (7) organization and project management risks; (8) product family and brand positioning risks; (9) product technology risks; (10) screening and appraisal risks; (11) supply chain and sourcing risks; and (12) trade customer risks. Their list of 142 risks includes metrics that could improve or deteriorate; desired conditions that could be achieved or not; objects that could succeed or fail; and other potential problems. Persson et al. (2009) considered the risks in geographically distributed software projects and identified risk areas based on the risk factors discussed in previous studies. They also matched the risk areas to the elements of the organization model presented by Leavitt (1964): task, structure, actors, and technology. The eight risk areas are the following: (1) task distribution; (2) knowledge management; (3) geographical distribution; (4) collaboration structure; (5) cultural distribution; (6) stakeholder relations; (7) communication infrastructure; and (8) technology setup. Wiggins and Hall (2016) identified 218 common risks in program management, which they grouped into six categories: (1) technical; (2) organizational; (3) operational; (4) enterprise; (5) management; and (6) external.

MacAdams and Pinto (2005) concluded in a literature review of risk management in software development projects that few deal with risk identification specific to software development and that risk management in software engineering has not received sufficient attention and development.

Analysing the problems that have occurred in past development projects can help a risk manager identify potential problems that could occur in future projects. For instance, Denning (2013) reviewed the problems that occurred during the development of the Boeing 787 Dreamliner (which suffered from overheating batteries) and identified the following categories of product development risks: coordination, innovation, outsourcing, partially implementing the Toyota model, offshoring, communication by computer, and labor relations. Stosic et al. (2017) and Škec et al. (2012) identified product development risks and when they may emerge using the risk breakdown structure (Hillson, 2002), which places risk events into three categories (management risk, technology risk, and market risk) and nine subcategories. This structure can be used with a work breakdown structure (WBS) to create a risk breakdown matrix that shows the risks associated with each task in the WBS. Table 2 lists categories of risks as internal risks and external risks using the proposed classification of Hillson (2002). A common issue in the literature described above is that lists of risks and categories of risk apply a mixed (and explicitly not articulated) categorization using both "categories of sources of uncertainty" (such as: changing customer demands) as well as "categories of impact areas" (such as: missed sales targets). For Table 2, we chose to use the three fundamental categories of sources of uncertainties that were present in the literature: management (e.g. risks arising from organization and processes), technology (e.g. risks arising from technology maturity), and market (e.g. risks arising from changing customer expectations). 
Table 2. Categories of risks identified in literature, by sources of uncertainty.

\begin{tabular}{|c|c|c|c|}
\hline Category & Internal & External & Reference \\
\hline \multirow{5}{*}{$\begin{array}{l}\text { Management } \\
\text { risk }\end{array}$} & $\begin{array}{l}\text { Coordination, communication by } \\
\text { computer, labor relations }\end{array}$ & \multirow{2}{*}{ Outsourcing, offshoring } & $\begin{array}{l}\text { Denning } \\
(2013)\end{array}$ \\
\hline & $\begin{array}{c}\text { Team (expertise, role division, } \\
\text { conflicts) }\end{array}$ & & $\begin{array}{c}\text { Jiang and Klein } \\
(2000)\end{array}$ \\
\hline & \multirow{2}{*}{ Geographical distribution } & $\begin{array}{c}\text { Stakeholder relation, cultural } \\
\text { distribution }\end{array}$ & $\begin{array}{l}\text { Persson et al. } \\
(2009)\end{array}$ \\
\hline & & $\begin{array}{l}\text { Supply chain and sourcing risks, } \\
\text { and trade customer risks }\end{array}$ & $\begin{array}{l}\text { Keizer et al. } \\
(2005)\end{array}$ \\
\hline & $\begin{array}{c}\text { Budget, objectives and requirements, } \\
\text { infrastructure and equipment, skillset } \\
\text { and human resources, }\end{array}$ & Supplier, legal and regulatory & $\begin{array}{l}\text { Oehmen et al. } \\
\qquad(2006)\end{array}$ \\
\hline \multirow{3}{*}{$\begin{array}{l}\text { Technology } \\
\text { risk }\end{array}$} & Innovation & & $\begin{array}{c}\text { Denning } \\
(2013)\end{array}$ \\
\hline & & $\begin{array}{l}\text { Technology complexity, product } \\
\text { technology }\end{array}$ & $\begin{array}{l}\text { Jiang and Klein } \\
\text { (2000) }\end{array}$ \\
\hline & Screening and appraisal risks, & Manufacturing technology risks, & $\begin{array}{l}\text { Keizer et al. } \\
(2005)\end{array}$ \\
\hline \multirow{4}{*}{ Market risk } & & Implementation & \multirow{2}{*}{$\begin{array}{l}\text { Jiang and Klein } \\
\text { (2000) }\end{array}$} \\
\hline & & $\begin{array}{c}\text { Lack of user expertise, lack of } \\
\text { customer support }\end{array}$ & \\
\hline & $\begin{array}{l}\text { Product family and brand } \\
\text { positioning risks }\end{array}$ & $\begin{array}{c}\text { Commercial viability risks, } \\
\text { competitor risks, consumer } \\
\text { acceptance and marketing risks, } \\
\text { public acceptance risks, } \\
\text { intellectual property risks }\end{array}$ & $\begin{array}{l}\text { Keizer et al. } \\
\qquad(2005)\end{array}$ \\
\hline & & Market and customer & $\begin{array}{l}\text { Oehmen et al. } \\
\qquad(2006)\end{array}$ \\
\hline Other risks & & Political risks, sustainability risk & $\begin{array}{l}\text { Aven (2016); } \\
\text { Schulte and } \\
\text { Hallstedt } \\
\quad(2018)\end{array}$ \\
\hline
\end{tabular}

\subsection{Risk assessment}

Given a possibly very long list of risks, risk managers need to classify and prioritize them in order to understand which ones need attention and to allocate resources. This is based on risk assessment, which determines the likelihood and consequences of each risk. Hubbard (2009) identified the following categories of assessment also described by ISO 31010: expert intuition, expert audit, simple stratification methods (such as red-yellow-green "scoring" methods), weighted scores, traditional financial analysis (without probabilities), a calculus of preferences (e.g. multi criteria decision making), and probabilistic methods (based on subjective input, historical data, and empirical data). Hubbard described the potential issues and pitfalls with the various approaches, particularly the widespread usage of simple scoring methods and their need for calibration. Although intuitive approaches for estimating the likelihood and consequences are common, researchers have described systematic techniques for assessing the likelihood and consequences of risks in design. Keizer et al. (2002) presented a risk management approach that includes listing the risks (stated in a neutral way) and asking subject matter experts to assess the following items for each risk statement: "What is the level of certainty that the statement will be true?" "What is the team's ability to influence the course of action?" and "What is the relative importance of the statement for obtaining project success?" The expert's answer for each question is a value on a five-point ordinal scale from "very low" to "very high." 
To assess the risks in the development of a new coffee product, Stosic et al. (2017) listed the tasks and risks in a risk breakdown matrix; assessed the risk associated with each task by considering each subcategory of risk, determining its probability of occurrence, and its impact (on a scale from 0 to 1); and calculated the total risk for each task (the sum of the expected impacts). They also determined the total risk for each subcategory by adding the expected impacts of the tasks. Motivated by the need to assess the risks associated with including customers into the product development process, Song et al. (2013) presented a risk assessment approach based on the Analytic Hierarchy Process for quantifying the subjective, qualitative aspects of these risks. In their review of uncertainty quantification, Tegeltija et al. (2016) discussed methods for quantifying epistemic uncertainty, including imprecise probabilities, the Dempster-Shafer theory of evidence, and the NUSAP scheme, which provides additional information about the data used to generate a value and assess its uncertainty (Funtowicz and Ravetz, 1990). Risk managers in product development projects could use these techniques for risky situations in which epistemic uncertainty (not aleatory uncertainty) dominates.

To assess consequences, one can use a model of the product development project. Project management tools such as the critical path method or PERT could be used to evaluate the impact of a task taking more time than it was allotted. Browning and Eppinger (2002) introduced using a design structure matrix (DSM) and simulation to evaluate the impact of iteration on cost and schedule. Browning et al. (2002) proposed an approach for measuring and tracking the expected disutility if the system design is unable to meet requirements. Several emerging types of risks, e.g. political risks and sustainability risks, that can profoundly affect product development organizations, are characterized by "deep uncertainty", i.e. both their likelihood and consequences are difficult to assess with any reasonable precision (Aven, 2016; Schulte and Hallstedt, 2018).

\subsection{Risk mitigation}

After determining which potential risks are critical, the risk manager must decide which risk mitigation actions to pursue in order to treat the risk. Although mitigation strategies have been categorized as transfer, reduce, and avoid, this view has been criticized (Hubbard, 2009) because a multitude of implicit and explicit mitigation strategies exists. These include preventive, reactive, responsive and adaptive, decisionmaking strategies, resilience strategies, and product design strategies, such as modular design. The choice of development process itself can also serve as a risk reducing strategy, since different types of product development processes reduce different types of risks. Bassler et al. (2011) analyzed the extent to which four product development approaches address risk, i.e. the waterfall model, spiral development, design for six sigma, and lean product development. To this end, they studied how those approaches include the four principles of risk-driven design, which are (i) identifying and quantifying risks; (ii) making risk-based decisions; (iii) reducing risks; and (iv) creating resilient product development systems. Cooper and More (1979) described the benefits of dividing a product development process into modules; in particular, they claimed that a modular approach reduces risk by spending money and resources incrementally and by resolving key uncertainties before beginning the next module. Within a product development process, setbased design pursues multiple concepts and delays concept selection until better information about each concept's performance is available (Sobek et al., 1999; Camarda et al., 2019). Pich et al. (2002) described the process of "vicarious selection" as "the process of introducing multiple new products into an unknown market and seeing which ones succeed." Lenfle (2011) identified two common strategies for dealing with risk in development projects with high uncertainty: learning through trial and error and parallel development. She concluded that parallel development involves cross-project learnings and combinations and iteration of the solution space. Learning through trial and error or prototyping is a common risk reduction technique in product development projects. Risk reduction through prototyping usually considers technical feasibility, desirability and functional testing (Den Ouden, 2012).

Beyond the selection of product development process, there are several techniques for mitigation: Persson et al. (2009) identified 35 risk resolution techniques and classified them into four areas based on the software risk management framework presented by McFarlan (1981): planning, control (track progress and manage discrepancies), social integration (connect participants and manage cultural differences), and technical integration (increase connectivity and technical compatibility). Hsiao et al. (2016) developed a risk mitigation taxonomy with eight categories of purposes and four categories of 
embodiments. Tang and Zimmerman (2009) described the Boeing 787 supply chain, the actions that Boeing took in response to problems, and the preventive actions that they could have used to avoid or reduce risks. Kayis et al. (2007) formulated the risk mitigation decision as an optimization problem that determines which risks should be mitigated subject to a budget constraint. A minimum cost-to-risk ratio first rule generated the best solutions in their experiments. Goswami and Tiwari (2014) formulated the problem of concept design selection as a risk mitigation decision that affects the likelihood of meeting targets for cost-effectiveness, reliability, and delivery time. Shah et al. (2012) used risk (expected costs due to failures) and value (performance) as criteria in a multi-attribute decision-making approach for selecting a manufacturing process during product development. Aven (2013) suggested robust decision making and adaptive risk analysis as strategies to manage risks with deep uncertainty (mentioned in Section 3). Cox (2012) reviewed ten decision-making tools that support risk mitigation under deep uncertainty and discussed how to use multiple models to make robust risk management decisions.

The selection of mitigation strategy as described above, must be balanced. Oehmen and Rebentisch (2010) identified the challenges of balancing the "cost of risks" and the "costs of risk mitigation" and deciding on an acceptable ratio of risk to return. In some cases, there may be insufficient time, money, personnel, or other resources to mitigate all of the important risks. In some cases, there may be multiple risk mitigation alternatives with different costs and impact; some may prevent a potential problem, and others may put in place resources and plans needed for contingency actions (which may never be used). Risk management in product development can benefit from tailoring the mitigation according to the contextual factors, type of innovation, type of uncertainty faced and the appropriate mitigation strategies (Oehmen et al., 2014; Škec et al., 2012; ISO, 2018; Grubisic et al., 2011).

\section{Discussion of empirical basis in literature}

One of the key challenges with risk management in product development is the difficulty in assessing the effectiveness of risk management processes and practices, such as risk identification, assessment, and mitigation. This is due to the fact that the true probabilities and potential consequences remain unknown. As a result, some product development teams may invest too much into risk management and mitigation activities, while others invest too little. Previous work on risk management in product development has identified a host of risk management practices and generated evidence that some methods are effective. The methods for identifying practices and generating evidence include surveys of practitioners, case studies, and empirical studies, except for Kayis et al. (2007), who used modelling and conducted computational experiments to evaluate approaches for making risk mitigation decisions.

\subsection{Surveys}

Škec et al. (2012) conducted a survey in which respondents identified the types of product development risks that they faced and the risk management methods that they used. Sicotte and Bourgault (2008) conducted a survey, receiving responses from 154 companies, to determine which types of uncertainty affect product development project performance. Olechowski et al. (2012) compared risk management practices of high performing product development projects with the practices of low performing ones. Based on the results of a survey, Oehmen et al. (2014) further identified six types of risk management practices as being most effective: (1) developing risk management skills and resources; (2) tailoring risk management to and integrate it with new product development; (3) quantifying impacts of risks on the organization's main objectives; (4) supporting all critical decisions with risk management results; (5) monitoring and reviewing risks, risk mitigation actions, and risk management process; and (6) creating transparency regarding new product development risks. They concluded that using risk management practices improves product development decision making, program stability, and problem solving. Jiang and Klein (2000) used the results of a survey of project managers to determine which risks have the most impact on software and information system development project effectiveness. The results suggest which risk mitigations are most important and should be effective. Persson et al. (2009) developed an online risk management tool that was evaluated by software developers and project managers from five IT companies in multiple cycles of refinement and evaluation. The evaluators found that the tool was useful for increasing awareness of the risks associated with geographically distributed software projects. de Bakker (2011) 
interviewed 19 stakeholders from seven ERP implementation projects; these stakeholders claimed that, among all risk management activities, risk identification was most critical to project success. Stosic et al. (2017) conducted a survey of organizations in Serbia; only 13\% to $15 \%$ of the respondents stated that they identified risks, defined mitigation procedures, and developed contingency plans. Mu et al. (2009) conducted a survey of 217 companies and an in-depth study of risk management in new product development. The researchers found project performance to be associated with managing risk, particularly regarding market, technical and organizational sources of risk.

\subsection{Case studies}

Keizer et al. (2002) described how Unilever conducted pilot studies that tested a formal risk management process and generated positive feedback from those who participated (documented in surveys of Unilever staff). Based on these results, Unilever adopted the process for its most important product development projects. Lenfle (2011) described how the managers of the Manhattan Project strategically managed resources and options as they modified their original parallel development approach by combining technical solutions within a modular framework to achieve their goals in the presence of significant technical risks. Hsiao et al. (2016) analysed 822 risk mitigation actions from a large engineering design organization. Camarda et al. (2019) discussed set-based design in a Finnish R\&D organization. Tang and Zimmerman (2009) and Denning (2013) both discussed a negative example by describing how Boeing's failure to manage risk appropriately during the development of the 787 led to excessive costs and delays. Bowers and Khorakian (2014) studied risk management practices at five manufacturing companies by interviewing 40 product development staff from multiple functions. They found that, although the companies did not use formal risk analysis methods, some interviewees recognized the need for explicit risk management, especially after the creative front end.

\subsection{Empirical studies}

de Bakker (2011) conducted an experiment in which 53 project groups completed the same project with different types of risk identification, which led to statistically different levels of project performance. Oehmen et al. (2014) reviewed earlier empirical studies that considered how risk management affects the success of product development processes. Thamhain (2013) conducted a field study of risk management in 35 product development projects. The researcher found that risks affect projects differently. The study points to the critical importance of dealing with risks early, aligning the strategic objectives and using multi-disciplinary teams in the management of risk. In other cases, researchers have documented practices that product development organizations use (Schulte and Hallstedt, 2017). Although this does not provide objective evidence that such practices are effective, their use suggests that these organizations consider them effective. However, there is growing evidence that risk management is sometimes ineffective despite the existence of risk management methods and tools (Kutsch et al., 2014). According to Akram and Pilbeam (2015) this ineffectiveness can be attributed to the fact that methods and tools should be supported by critical success factors such as integration of stakeholders into the risk management activities. Willumsen et al. (2019) conducted an empirical study of the perceptions of risk management practices. The results showed that stakeholder perceptions influence the perceived effectiveness of risk management practices. Integrating stakeholders is especially important during risk identification, as discussed in Section 3.1. De Carvalho et al. (2015) reviewed the empirical studies on effectiveness of risk management in projects and found that they produce conflicting results. The researchers concluded that this might be due to organizational culture, climate and demographics and individual aspects such as expectations, intuition, judgement, bias, power conflicts, trust and learning.

\section{Summary and conclusions}

This paper has reviewed literature on risk management practices and methods in product design and development. The review divided the literature into three key areas: risk identification, risk assessment, and risk mitigation. In each area, researchers have both described practices that are used in product development organizations and proposed new methods to support risk management processes and decision-making. This paper has also discussed the types of evidence used to evaluate the effectiveness 
of risk management activities. The variety inherent in product design and development makes it nonsensical to prescribe a specific set of risk management practices for every product development organization. This review, however, should be useful to practitioners and researchers, since it provides a framework for understanding and navigating previous literature, which also can help organizations to tailor their risk management practices, as recommended by ISO 31010 and Oehmen et al. (2014).

Effective and efficient risk management must be chosen for a particular product development case and different risk management techniques fit different contexts as have been described in the previous sections. There is a wide range of options when it comes to risk management and knowledge about the various methods and techniques in both theory and practice as presented in this paper is relevant for tailoring risk management in product development. However, more research is needed and opportunities for additional research were identified as the following: risk mitigation decision-support tools that account for multiple uncertainties and multiple objectives (including cost, time, and profitability); implementing, testing, and refining proposed methods; collecting additional evidence for the effectiveness of risk management practices; and developing conceptual models of product development that can be used to understand why certain design processes and methods effectively manage risk.

\section{Acknowledgements}

This paper began as a workshop sponsored by the Risk Management Processes and Methods in Design SIG at the 2017 International Conference on Engineering Design. Sincere thanks to the following persons, who also participated in that workshop: Charlotte Asbjørn Sörensen, Anna Klapwijk, Eric Reynolds Brubaker, Francois Houde, Sophie I. Hallstedt, Tanawan Wee, and Torsten Erbe. Financial support from the Knowledge Foundation in Sweden is gratefully acknowledged.

\section{References}

Akram, M. and Pilbeam, C. (2015), “Critical Success Factors for Effective Risk Management in New Product Development", International Conference on Industrial Engineering and Systems Management (IESM), pp. 1205-1212. https://doi.org/10.1109/IESM.2015.7380306

Aven, T. (2013), "On How to Deal with Deep Uncertainties in a Risk Assessment and Management Context", Risk Anal., Vol. 33, pp. 2082-2091. https://doi.org/10.1111/risa.12067

Aven, T. (2016), "Risk assessment and risk management: Review of recent advances on their foundation", Eur. J. Oper. Res., Vol. 253, pp. 1-13. https://doi.org/10.1016/j.ejor.2015.12.023

Bassler, D., et al. (2011), "A comparison of the integration of risk management principles in product development", Proceedings of the 18th International Conference on Engineering Design (ICED11), The Design Society, Glasgow, Vol. 3, pp. 306-316.

de Bakker, K. (2011), "Communicative Project Risk Management in IT Projects", European Journal for the Informatics Professional, Vol. 12 No. 5, pp. 59-66.

de Carvalho, M.M. and Rabechini Junior, R. (2015), "Impact of risk management on project performance: The importance of soft skills", International Journal of Production Research, Vol. 53, pp. 321-340. https://doi.org/10.1080/00207543.2014.919423

Bowers, J. and Alireza, K. (2014), "Integrating risk management in the innovation project", European Journal of Innovation Management, Vol. 17 No. 1, pp. 25-40. https://doi.org/10.1108/EJIM-01-2013-0010

Browning, T.R. and Eppinger, S.D. (2002), "Modeling impacts of process architecture on cost and schedule risk in product development", IEEE Transactions on Engineering Management, Vol. 49, p. 4. https://doi.org/ 10.1109/TEM.2002.806709

Browning, T.R., et al. (2002), "Adding value in product development by creating information and reducing risk", IEEE Transactions on Engineering Management, Vol. 49, pp. 4. https://doi.org/10.1109/TEM.2002.806710

Camarda, C.J., et al. (2019). "Rapid product development methods in practice-case studies from industrial production and technology development," In International Society for Professional Innovation Management (ISPIM) Conference Proceedings, pp. 1-17.

Cooper, R.G. and More, R.A. (1979), "Modular risk management: an applied example", R\&D Management, Vol. 9 No. 2, pp. 93-99. https://doi.org/10.1111/j.1467-9310.1979.tb00140.x

Cox, L.A. (2012), "Confronting Deep Uncertainties in Risk Analysis”, Risk Analysis, Vol. 32, pp. 1607-1629. https://doi.org/10.1111/j.1539-6924.2012.01792.x

Denning, S. (2013), "What went wrong at Boeing", Strategy \& Leadership, Vol. 41 No. 3, pp. 36-41. https://doi.org/10.1108/10878571311323208 
Funtowicz, S. and Ravetz, J. (1990), Uncertainty and Quality in Science for Policy Research, Kluwer Academic Publishers. https://doi.org/10.1007/978-94-009-0621-1

Goswami, M. and Tiwari, M.K. (2014), “A predictive risk evaluation framework for modular product concept selection in new product design environment", Journal of Engineering Design, Vol. 25 No. 1-3, pp. 150-171.

Grubisic, V.V.F., Gidel, T. and Ogliari A. (2011), "Recommendations for Risk Identification Method Selection According to Product Design and Project Management Maturity, Product Innovation Degree and Project Team", Proceedings of the 18th International Conference on Engineering Design (ICED), The Design Society, pp. 187-198.

Herrmann, J.W. (2015), Engineering Decision Making and Risk Management, John Wiley and Sons, Hoboken, New Jersey. https://doi.org/10.1080/09544828.2014.921806

Hillson, D. (2002), "Use a risk breakdown structure (RBS) to understand your risks", Paper presented at Project Management Institute Annual Seminars \& Symposium, San Antonio, TX, Project Management Institute, Newtown Square, PA.

Hsiao, C., et al. (2016), "Discovering taxonomic structure in design archives with application to risk-mitigating actions in a large engineering organisation", Journal of Engineering Design, Vol. 27 No. 1-3, pp. 146-169.

Hubbard, D. (2009), The Failure of Risk Management: Why It's Broken and How to Fix It, Wiley.

ISO (2009), IEC/ISO 31010 Risk management - Risk assessment techniques, International Organization for Standardization, Geneva.

ISO (2018), ISO 31000:2018 Risk management - Guidelines, International Organization for Standardization, Geneva.

Jiang, J. and Klein, G. (2000), "Software development risks to project effectiveness", Journal of Systems and Software, Vol. 52 No. 1, pp. 3-10. https://doi.org/10.1016/S0164-1212(99)00128-4

Kaplan, R.S. and Mikes, A. (2012), "Managing Risks: A New Framework", Harvard Business Review, Vol. 90 No. 6.

Kayis, B., et al. (2007), "A risk mitigation methodology for new product and process design in concurrent engineering projects", CIRP Annals-Manufacturing Technology, Vol. 56 No. 1, pp. 167-170. https://doi.org/10.1016/j.cirp.2007.05.040

Keizer, J.A., Halman, J. and Song, M. (2002), "From experience: applying the risk diagnosing methodology", Journal of Product Innovation Management, Vol. 19 No. 3, pp. 213-232. https://doi.org/10.1016/S07376782(02)00138-8

Keizer, J.A., Vos, J.-P. and Halman, J. (2005), "Risks in new product development: devising a reference tool", R\&D Management, Vol. 35 No. 3, pp. 297-309. https://doi.org/10.1111/j.1467-9310.2005.00391.x

Kutsch, E., Browning, T.R. and Hall, M. (2014), "Bridging the risk gap", Research Technology Management, Vol. 57 No. 2, pp. 26-32.

Leavitt, H.J. (1964), “Applied organization change in industry: Structural, technical, and human approaches", Proc. New Perspect. Organ. Res., Vol. 1964, pp. 55-71.

Lehtiranta, L. (2014), "Risk perceptions and approaches in multi-organizations: A research review 2000-2012", International Journal of Project Management, Vol. 32 No. 4, pp. 640-653. https://doi.org/10.1016/ j.ijproman.2013.09.002

Lenfle, S. (2011), "The strategy of parallel approaches in projects with unforeseeable uncertainty: the Manhattan case in retrospect", International Journal of Project Management, Vol. 29, p. 4. https://doi.org/10.1016/ j.ijproman.2011.02.001

MacAdams, K.G. and Pinto, C.A. (2005), "Software development project risk management: A literature review", 26th Annual National Conference of the American Society for Engineering Management, pp. 635-641.

McFarlan, F.W. (1981), "Portfolio approach to information systems", Harvard Business Review, Vol. 59 No. 5 , pp. 142-150.

Mu, J., Peng, G. and MacLachlan, D.L. (2009), "Effect of Risk Management Strategy on NPD Performance", Technovation, Vol. 29 No. 3, pp. 170-180. https://doi.org/10.1016/j.technovation.2008.07.006

NASA (2011), Risk Management Handbook, Washington D.C., Available online: https://ntrs.nasa.gov/archive/nasa/casi.ntrs.nasa.gov/20120000033.pdf, Accessed January 5, 2019.

Oehmen, J. and Rebentisch, E. (2010), "Risk Management in Lean Product Development", Lean Advancement Initiative.

Oehmen, J. and Seering, W. (2011), "Risk-Driven Design Processes: Balancing Efficiency with Resilience", In: Birkhofer, H. (Ed.), The Future of Design Methodology, Springer, pp. 44-54. http://dx.doi.org/10.1007/9780-85729-615-3

Oehmen, J., et al. (2006), "Risk Management in Product Development - Current Methods", Proceedings of the DESIGN 2006 / 9th International Design Conference, Vol. 12, pp. 1551-1558.

Oehmen, J., et al. (2010), "Risk management in product design: Current state, conceptual model and future research", ASME 2010 International Design Engineering Technical Conferences and Computers and 
Information in Engineering Conference, pp. 1033-1041. American Society of Mechanical Engineers. https://doi.org/10.1115/DETC2010-28539

Oehmen, J., et al. (2014), "Analysis of the effect of risk management practices on the performance of new product development programs", Technovation, Vol. 34 No. 8, pp. 441-453. https://doi.org/10.1016/ j.technovation.2013.12.005

Olechowski, A., et al. (2012), "Characteristics of successful risk management in product design”, Proceedings of the DESIGN 2012 / 12th International Design Conference, The Design Society, Glasgow, pp. 269-278.

Olechowski, A.L. (2012), Product development risk management and the role of transparency, Massachusetts Institute of Technology.

Den Ouden, E. (2012), Innovation Design: Creating Value for People, Organizations and Society, Springer, London.

Persson, J.S., et al. (2009), "Managing risks in distributed software projects: an integrative framework", IEEE Transactions on Engineering Management, Vol. 56 No. 3, pp. 508-532. https://doi.org/10.1109/TEM. 2009.2013827

Pich, M.T., Loch, C.H. and De Meyer, A. (2002), "On uncertainty, ambiguity, and complexity in project management”, Management Science, Vol. 48 No. 8, pp. 1008-1023. https://doi.org/10.1287/mnsc.48.8. 1008.163

Purdy, G. (2010), "ISO 31000:2009 - Setting a new standard for risk management", Risk Analysis: An Official Publication of the Society for Risk Analysis. https://doi.org/10.1111/j.1539-6924.2010.01442.x

Reinertsen, D.G. (1997), Managing the Design Factory: A Product Developer's Toolkit, The Free Press, New York.

Schulte, J. and Hallstedt, S.I. (2018), "Company Risk Management in Light of the Sustainability Transition", Sustainability, Vol. 10, p. 4137. https://doi.org/10.3390/su10114137

Schulte, J. and Hallstedt, S.I. (2018), "Risk Management Practices in Product Development Companies", Proceedings of NordDesign 2018, Linköping, Sweden, August 14-17, 2018, The Design Society.

Shah, L., et al. (2012), "(Value, Risk)-based Performance Evaluation of Manufacturing Processes", IFAC Proceedings, Vol. 45 No. 6, pp. 1586-1591. https://doi.org/10.3182/20120523-3-RO-2023.00145

Sicotte, H. and Bourgault, M. (2008), "Dimensions of uncertainty and their moderating effect on new product development project performance", R\&D Management, Vol. 38 No. 5, pp. 468-479. https://doi.org/10. $1111 /$ j.1467-9310.2008.00531.x

Škec, S., et al. (2012), "Mapping risks in product development", Proceedings of the DESIGN 2012 / 12th International Design Conference, The Design Society, Glasgow, Vol. 1, pp. 311-320.

Škec, S., et al. (2014), "Tailoring risk management approach for the product development environment", Proceedings of the DESIGN 2014 / 13th International Design Conference, The Design Society, Glasgow, pp. 385-396.

Sobek, D.K., Ward, A.C. and Liker, J.K. (1999), "Toyota's Principles of Set-Based Concurrent Engineering", Sloan Management Review, pp. 67-83.

Song, W., Ming, X. and Xu, Z. (2013), "Risk evaluation of customer integration in new product development under uncertainty", Computers \& Industrial Engineering, Vol. 65 No. 3, pp. 402-412. https://doi.org/10. 1016/j.cie.2013.04.001

Stosic, B., et al. (2017), "Risk identification in product innovation projects: new perspectives and lessons learned", Technology Analysis \& Strategic Management, Vol. 29 No. 2, pp. 133-148. https://doi.org/10. 1080/09537325.2016.1210121

Tang, C.S. and Zimmerman, J.D. (2009), "Managing New Product Development and Supply Chain Risks: The Boeing 787 Case", Supply Chain Forum: An International Journal, Vol. 10, pp. 74-86. https://doi.org/ 10.1080/16258312.2009.11517219

Tegeltija, M., et al. (2016), "Post-probabilistic uncertainty quantification: Discussion of potential use in Product Development Risk Management", Proceedings of the DESIGN 2016 / 14th International Design Conference, The Design Society, Glasgow, Vol. 84, pp. 533-542.

Thamhain, H. (2013), "Managing Risks in Complex Projects", Project Management Journal, Vol. 44 No. 2, pp. 20-35. https://doi.org/10.1002/pmj.21325

Wiggins, L. and Hall, D. (2016), "The Missing Link - Risk Identification", presentation to the Risk SIG, December 2016.

Willumsen, P., et al. (2017), “Applying lean thinking to risk management in product development”, Proceedings of the 21st International Conference on Engineering Design (ICED 17), Vancouver, Canada, The Design Society, Glasgow.

Willumsen, P., et al. (2019), "Value creation through project risk management", International Journal of Project Management. https://doi.org/10.1016/j.ijproman.2019.01.007

Wohlin, C. (2014), "Guidelines for snowballing in systematic literature studies and a replication in software engineering", Proceedings of the 18th International Conference on Evaluation and Assessment in Software Engineering - EASE '14, ACM Press, New York, USA, pp. 1-10. https://doi.org/10.1145/2601248.2601268 